J. Lake Sci.(湖泊科学), 2009, 21(6): 885-890 http://www.jlakes.org. E-mail: jlakes@niglas.ac.cn (C)2009 by Journal of Lake Sciences

\title{
内蒙古乌梁素海不同形态氮的时空分布*
}

\author{
李 兴 ${ }^{1}$, 李畅游 ${ }^{* *}$, 李卫平 ${ }^{1,2}$, 史小红 ${ }^{1}$, 代文婕 ${ }^{3}$, 勾芒芒 ${ }^{4}$ \\ (1: 内蒙古农业大学水利与土木建筑工程学院, 呼和浩特 010018) \\ (2: 内蒙古科技大学能源与环境学院, 包头 014010) \\ (3: 内蒙古满洲里市建设局, 满洲里 021400) \\ (4: 内蒙古自治区水利科学研究院, 呼和浩特 010020)
}

摘 要: 为揭示不同形态氮在乌梁素海空间分布特征及变化规律, 运用 ArcGIS 统计模块分析了 2006-2007年乌梁素海不同形 态氮浓度的时空变异. 研究表明: 乌梁素海水体中各监测点总氮浓度夏、冬季高, 秋季低, 季节性差异较为明显; 秋、冬季氨 氮平均浓度明显高于夏季; 不同季节亚硝态氮平均浓度明显高于硝态氮. 在空间分布上，乌梁素海不同形态氮浓度分布呈现 出由北向南逐渐降低的趋势. 总之, 乌梁素海氮素污染问题已十分严重, 主要污染源为河套灌区农田排水、沿总干渠区域的工 业废水和生活污水，随水体的流动氮污染减少，但某些区域因芦苇、水草密集而使不同形态氮有不同程度的增减.

关键词: 乌梁素海; 不同形态氮; 时空分布; ArcGIS

\section{Temporal and spatial distribution of different species of nitrogen in Lake Wuliangsuhai, Inner Mongolia}

\author{
LI Xing ${ }^{1}$, LI Changyou ${ }^{1}$, LI Weiping ${ }^{1,2}$, SHI Xiaohong ${ }^{1}$, DAI Wenjie ${ }^{3}$ \& GOU Mangmang ${ }^{4}$ \\ (1: The College of Water Conservancy and Civil Engineering, Inner Mongolia Agricultural University, Hohhot 010018, P.R.China) \\ (2: The College of Environment \& Energy Resources, Inner Mongolia University of Science \& Technology, Baotou 014010, \\ P.R.China) \\ (3: Construction Bureau of Manzhouli City, Manzhouli 021400, P.R.China) \\ (4: Institute of Water Conservancy Science Inner Mongolia Municipality, Hohhot 010020, P.R.China)
}

Abstract: The temporal and spatial variation characteristics of nitrogen forms are very important for environmental pollution control of lake. Concentrations of different nitrogen forms were studied using the geostatistical analysis module of ArcGIS in Lake Wuliangsuhai. The results indicate that average concentrations of total nitrogen were higher in summer and winter than autumn in seasonal time series, the average concentrations of ammonia nitrogen were lower in summer than autumn and winter, and the average concentration of nitrite nitrogen was higher than nitrate nitrogen in different seasons. In space, concentration distribution of different forms of nitrogen showed gradually decreasing from north to south. In a word, nitrogen pollution is very serious in Lake Wuliangsuhai. The main pollutions were sourced from farm field drainage of the Hetao irrigated areas, industrial waste water and domestic sewage close to main irrigation canal, which caused different forms of nitrogen contents decreases with the discharge of flowing water. However, in the region of density reed and aquatic, the contents of nitrogen forms will change with increase or decrease.

Keywords: Lake Wuliangsuhai; forms of nitrogen; spatial-temporal distribution; ArcGIS

当前, 湖泊水环境质量逐渐恶化, 富营养化程度不断加剧，不同营养物质的数量及其存在形态与污染

* 国家自然科学基金项目(50569002, 50669004)和内蒙古自然科学基金重点项目(200711020604)联合资助. 2008-12-19收 稿; 2009-03-30收修改稿. 李兴, 男, 1981年生, 博士; E-mail: lixingmm@yahoo.com.cn.

** 通讯作者; E-mail: nndlichangyou@163.com. 
成因有着显著的关系. 氮不仅是水体中生物的营养元素，也是富营养化成因的主要限制性元素之一 ${ }^{[1-4]}$, 湖水中含氮化合物与初级生产力、次级生产力有着密切的关系, 它是浮游植物和挺水植物生长动力的三 大要素之一, 在水生生物活动中起着重要的作用. 湖水中以溶解性无机氮形式存在的含氮化合物主要为 氨氮 $\left(\mathrm{NH}_{4}{ }^{+}-\mathrm{N}\right)$ 、硝态氮 $\left(\mathrm{NO}_{3}{ }^{-}-\mathrm{N}\right)$ 、亚硝态氮 $\left(\mathrm{NO}_{2}^{-}-\mathrm{N}\right)$, 无机氮经水生植物吸收、转变等过程变为有机氮, 当 水生植物在循环排泄或衰老死亡分解时, 不同形式的有机氮又被释放出来, 经过菌类的分解作用, 又转 化为各种形式的无机氮, 因此不同形态的无机氮在氮循环及收支平衡中起到至关重要的作用.

近年来, 国内外对氮的研究主要为: 氮素在系统中的收支平衡 ${ }^{[5]}$ 、不同形态氮对水生动植物活动的影 响 ${ }^{[6-10]}$ 、不同形态氮间相关性分析 ${ }^{[11-12]}$ 、湖泊底泥中不同形态氮的空间分布 ${ }^{[13-14]}$ 、不同形态氮在地表水 体中时空分布规律 ${ }^{[15-16]}$ 等等, 但对于不同形态氮在湖泊水体中变异性的研究很少. 研究湖泊水体中营养 物质存在形态的时空分布规律, 对深人了解营养物质的循环和转换以及研究富营养化机理和实际控制具 有一定的意义.

\section{1 研究区概况}

乌梁素海 $\left(40^{\circ} 36^{\prime}-41^{\circ} 03^{\prime} \mathrm{N}, 108^{\circ} 43^{\prime}-108^{\circ} 57^{\prime} \mathrm{E}\right)$ 是内蒙古西部最大的淡水湖泊, 位于黄河河套平原的末 端，西临河套灌区，东靠乌拉山西麓，现有面积 $293 \mathrm{~km}^{2}$ ，南北长 35-40km，东西宽 5-10km，湖面平均高 程为 $1018.5 \mathrm{~m}, 80 \%$ 的水域水深为 $0.8-1.0 \mathrm{~m}$, 乌梁素海前身为黄河故道, 内蒙古巴彦淖尔盟河套灌区 $200 \mathrm{~km}$ 的排水总干渠流经乌梁素海再注人黄河. 乌梁素海是典型的草-藻型湖泊, 其中芦苇面积占全湖 $44 \%$ 左右, 主要分布在北部小海子区、乌梁素海中部区和湖滨带. 该湖的人湖污染物除承纳农田灌溉排水 外, 沿总干渠杭锦后旗、五原等地区的工业废水与生活污水也汇入总干渠. 对湖泊水质与富营养化产生 较大的影响. 乌梁素海已成为一个富营养化污染程度非常严重的湖泊, 氮、磷的浓度含量大都超出了地 表水环境质量标准(GB3838-2002) V 类要求, 严重影响着湖区周围人民的生产、生活和健康.

\section{2 材料与方法}

按照我国水环境及湿地生态系统调查规范 ${ }^{[17]}$, 根据乌梁素海污染源的分布和水动力特征, 将乌梁素 海在空间上以 $2 \mathrm{~km} \times 2 \mathrm{~km}$ 的正方形网格进行剖分, 使用网格的交点, 以梅花形布置取样监测点. 芦苇或水 草密集、水深过浅处的取样点，采样船不能到达布置点进行取样，小海子芦苇密集且水深不足 $50 \mathrm{~cm}$, 因 此没有监测点, 常年监测点只有 25 个, 占全湖面积的 $75 \%$ 左右, 其它采样点并不连续. 采样点位置利用 GPS 定位，分别于 2006 年 6 月、 8 月、10 月和 2007 年 1 月在乌梁素海采集了上覆水体样品，测试指标 及具体检测方法分别为: 总氮: GB/T 11891-1989; 氨氮: 国家环境保护总局《水和废水监测分析方法》; 硝 态氮: GB/T 7480-1987; 亚硝态氮: GB/T 7493-1987.

\section{3 不同形态氮浓度的时空分布}

乌梁素海不同形态氮的分布与各种化学、生物及物理等环境因素有着极为密切的关系, 不同形态氮 浓度在不同时期的具体分布情况见图 1 和图 2.

\section{1 季节差异}

上覆水体中不同监测点总氮浓度季节性差异较为明显, 水生生物活动频繁的夏季总氮浓度很高(图 1), 原因可能与人湖农业废水含氮浓度较高有关; 此外, 夏季水体温度逐渐上升、风速大, 对于浅水湖泊 而言, 上下水体混合较好, 乌梁素海为草型湖泊, 尽管悬浮作用不强, 但含氮沉积物向上的充分释放仍 有一定贡献. 进入秋季, 总氮平均浓度降低 $26.4 \%$. 王东红 ${ }^{[15]}$ 等研究认为: 上覆水体中总氮浓度冬季明显 高于夏、秋季, 造成这种差异的原因可能为北方和南方气候上的差异以及温度对内源释放的影响. 就乌 梁素海而言, 原因主要与该时期河套灌区进行大面积秋浇控盐，排水量加大，湖泊水位明显升高有关. 因此，对水中污染物质浓度起到稀释作用，使得该时期总氮浓度下降; 进人冬季，由于没有农田排水的 补给, 人湖水量明显减少, 主要补给水量为地下水和沿总干渠区域的工业废水和生活污水, 所以因排人 水量减少使得总氮平均浓度较秋季有所增加(19.4\%). 

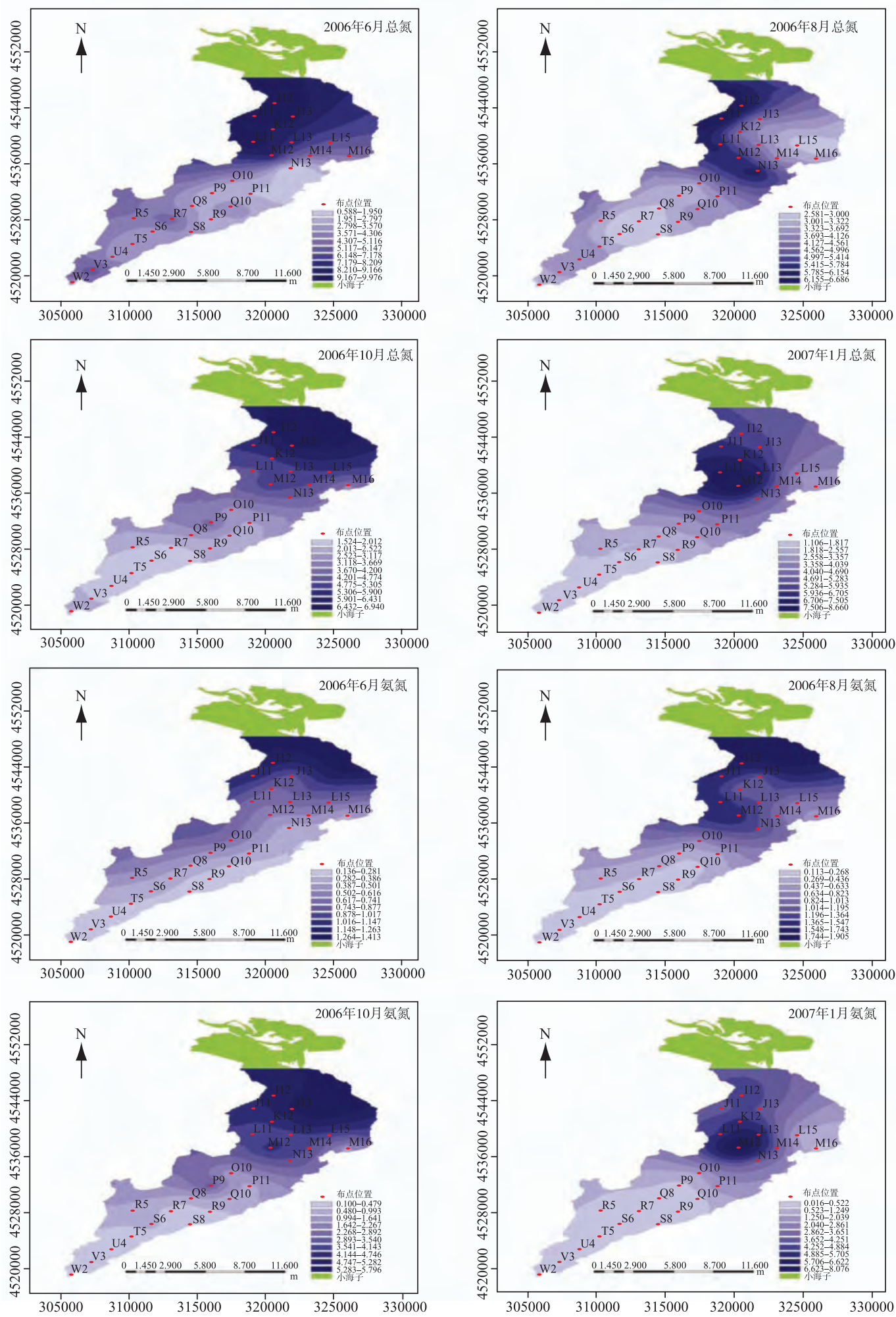

图 1 乌梁素海 2006 年、2007 年总氮和氨氮空间分布结果

Fig.1 Spatial distribution of total nitrogen and ammonia nitrogen in Lake Wuliangsuhai in 2006 and 2007 

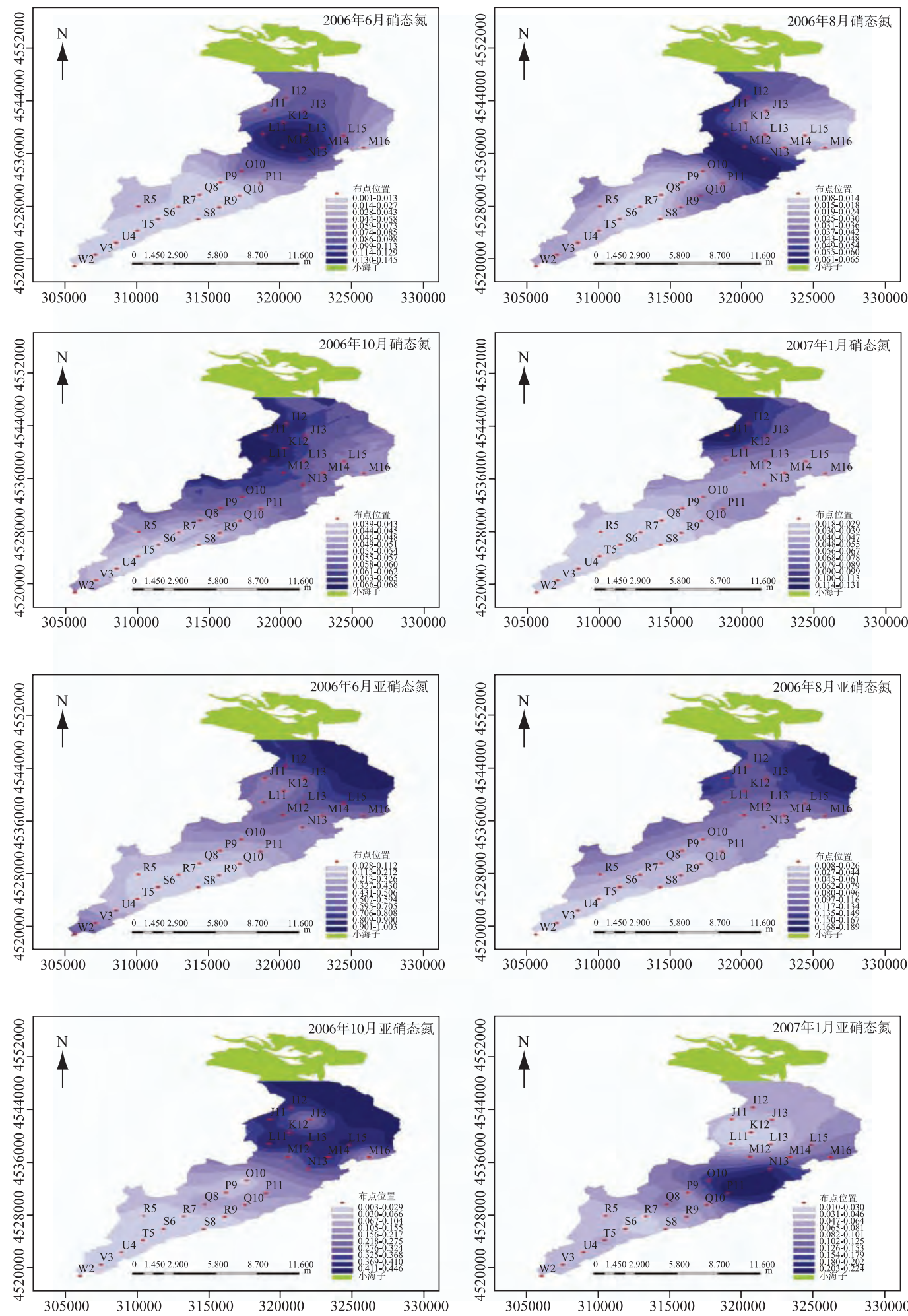

图 2 乌梁素海 2006 年、2007 年硝态氮和亚硝态氮空间分布结果

Fig.2 Spatial distribution of nitrate nitrogen and nitrite nitrogen in Lake Wuliangsuhai in 2006 and 2007 
2006 年 10 月和 2007 年 1 月不同监测点氨氮平均浓度与 2006 年 6 月、 8 月相比明显升高, 这说明秋、 冬两个季节水体中反硝化作用和氨化作用很强, 导致水中氨氮浓度很高, 水体呈现还原态, 这与冬季表 层结冰底层水中溶解氧降低不无关系(图 1). 从硝态氮的时间分布上看, 除个别测点外, 各测点硝态氮浓 度变化不大，而这 4 个月的氨氮浓度都很高，2006年 6 月、 8 月、 10 月和 2007 年 1 月均值分别为 $0.73 \mathrm{mg} / \mathrm{L} 、$ $0.88 \mathrm{mg} / \mathrm{L} 、 2.74 \mathrm{mg} / \mathrm{L} 、 2.05 \mathrm{mg} / \mathrm{L}$ (图 2), 由此可知在乌梁素海湖泊水体中氨氮含量要远远高于硝态氮含量 和亚硝态氮含量. 因此，氨氮污染在总氮污染中占有相当的比例. 而且 2006 年 10 月和 2007 年 1 月不同 监测点氨氮平均浓度与 2006 年 6 月、 8 月相比明显升高, 属于劣 $\mathrm{V}$ 类水质.

\section{2 空间分布}

各月不同形态氮浓度在湖中分布具有明显的空间变异性，空间分布整体呈北高南低，由北至南逐渐 降低之势, 主要是由于带有大量农田排水、工业废水和生活污水的水流由人湖口向南部移动, 在流动过 程中被大量芦苇、水草、水藻等水生植物吸收, 加之随着水流移动污染物质会发生降解沉积作用. 2006 年 6 月和 8 月的硝态氮高浓度区集中在乌梁素海中部 $\left(\mathrm{M}_{12}\right.$ 点)附近，而 2006 年 10 月和 2007 年 1 月硝态 氮高浓度区却集中在 $\mathrm{M}_{12}$ 点的西北部(图 2), 分析其原因主要是乌梁素海中部是芦苇水草生长的密集区, 6 月和 8 月是温度和光照条件非常适宜的时期, 正是芦苇生殖生长的旺盛期, 芦苇、水草等水生植物通过 光合作用产生大量的氧气, 水中溶解氧浓度升高, 硝化作用增强, 因此使得该区域硝态氮的浓度达到全 湖最大，而 10 月和 1 月已分别进人秋季和冬季，芦苇已萎䔍、枯黄、腐烂，细菌分解将消耗水中大量的 溶解氧, 使得反硝化作用增强, 造成乌梁素海中部硝态氮浓度下降.

无论夏季还是秋季, 位于乌梁素海北部监测点的亚硝态氮浓度均明显高于南部监测点的亚硝态氮浓 度, 氨氮也有相同的分布特征. 表明北部反硝化作用和氨化作用强烈, 水体还原状态明显高于南部, 使 得北部富营养化程度高, 水质恶化严重. 2007 年 1 月, 乌梁素海 $\mathrm{P}_{11}$ 点附近形成了亚硝态氮高浓度区, 主 要是因为 $\mathrm{P}_{11}$ 点附近是全湖水草、水藻最密集的区域, 冬季大量水草水藻沉积在湖底淤积腐烂, 经过细菌 分解将消耗水体中大量溶解氧, 加之, 表层水结冰使得水体无法得到大气复氧, 最终导致溶解氧极度降 低, 反硝化作用加强, 亚硝态氮含量增加.

各月总氮浓度分布趋势与氨氮浓度分布趋势十分相似, 因为氨氮浓度大约占总氮浓度的 $50 \%$ 左右, 在无机氮中占有主要位置, 可见乌梁素海氮素污染严重, 氨氮和有机氮是氮素污染主要存在的形态. 因 此，控制氨氮数量对控制氮素污染将起到决定性作用(图 2).

从总体来看, 非冰冻期氨氮和亚硝态氮高浓度区主要集中在乌梁素海东北方向, 分析其原因主要是 乌梁素海东北区域为明水区, 没有芦苇生长, 失去了光合作用的产氧源, 同时也没有芦苇净化水质的条 件, 使得该区域缺氧严重, 氨化和反硝化作用强烈, 使得氨氮和亚硝态氮浓度很高; 而冰冻期氨氮和亚 硝态氮高浓度区受冰层阻隔大气复氧的影响, 集中在水草芦苇密集的中部区, 原因为大量水生植物沉积 水底腐烂分解消耗了大量溶解氧.

纵观整个湖区得知, 不同形态氮的高浓度区主要集中在湖泊人口附近的区域, 主要是由于上游河套 灌区总排干渠带有大量的污染物质排人乌梁素海, 尽管它拥有大量芦苇, 但由于其自净容量有限, 水体 仍然没能摆脱严重污染的局面. 总之, 人们在处理发展经济和保护水资源的矛盾中加剧了乌梁素海的水 质恶化, 是造成乌梁素海重度富营养化的主要原因. 本文利用时空分布图, 可以更直接地看出不同形态 氮在全湖的分布状况, 也有利于发现湖泊污染物质降解空间变化的过程和具有异常区域的点源污染位置. 因此, 对于不同区域采用不同的治理和修复措施更具有针对性参考价值.

\section{4 参考文献}

[1] 付春平, 钟成华, 邓春光. 水体富营养化成因分析. 重庆建筑大学学报, 2005, 27(1): 128-131.

[2] 蔡履冰. 太湖流域水体富营养化成因及防治对策的初步研究. 中国环境监测, 2003, 19(3): 52-54.

[3] 麻 军. 延庆西湖富营养化成因分析. 北京水利, 2005, 6: 8-9.

[4] 程丽巍, 许 海, 陈铭达等. 水体富营养化成因及其防治措施研究进展. 环境保护科学, 2007, 33(1): 18-21.

[5] 刘文祥. 人工湿地在农业面源污染控制中的应用研究. 环境科学研究, 1997, 10(4): 16-19. 
[6] 王 珺, 顾宇飞, 纪东成等. 富营养条件下不同形态氮对轮叶黑藻(Hydrilla verticillata)的生理影响. 环境科学研究, 2006, 19(1): 71-74.

[7] Serna MD, Legaz BF, Primo-millo E. The influence of nitrogen concentration and ammonium/nitrate ratio on N-uptake, mineral composition and yield of citrus. Plant and Soil, 1992, 147: 13-23.

[8] 王沛芳, 王 超, 王晓蓉等. 苦草对不同浓度氮净化效果及其形态转化规律. 环境科学, 2008, 29(10): 890-895.

[9] 沈根祥, 姚 芳, 胡 宏等. 浮萍吸收不同形态氮的动力学特性研究. 土壤通报, 2006, 37(3): 504-508.

[10] 金相灿, 楚建周, 王圣瑞. 水体氮浓度、形态对黑藻和狐尾藻光合特征的影响. 应用与环境生物学报, 2007, 13(2): 200-204.

[11] 胡 俊, 刘永定, 刘剑形等. 滇池沉积物间隙水中氮、磷形态及相关性的研究. 环境科学学报, 2005, 25(10): 1391-1396.

[12] Andersen JM. Effects of nitrate concentration in lake water on phosphate release from the sediment. Water Research, 1982, 16: 1119-1126.

[13] 俞海桥, 方 涛, 夏世斌. 疏浚及水生植被重建对太湖西五里湖表层沉积物中磷、氮含量及形态分布的影响. 农业环境科 学学报, 2007, 26(3): 868-872.

[14] 潘成荣, 李 凌, 叶琳琳等. 瓦埠湖沉积物中氮与磷赋存形态分析. 水资源保护, 2007, 23(4): 10-14.

[15] 王东红, 黄清辉, 王春霞等. 长江中下游浅水湖泊中总氮及其形态的时空分布. 环境科学, 2004, 25: 27-30.

[16] 秦巧燕, 贾陈忠, 金卫斌等. 荆州市区主要地表水中不同形态氮的分布特征. 长江大学学报(自科版), 2007, 4(2): 84-86.

[17] 吕宪国主编. 湿地生态系统观测方法. 北京: 中国环境科学出版社, 2005: 182. 